\title{
Impact of the 2006 Massachusetts health care insurance reform on neurosurgical procedures and patient insurance status
}

\author{
Nicolas W. Villelli, MD, ${ }^{1}$ Rohit Das, MD, ${ }^{2}$ Hong Yan, BS, ${ }^{3}$ Wei Huff, MD, PhD, ${ }^{1}$ Jian Zou, PhD, ${ }^{3}$ and \\ Nicholas M. Barbaro, MD'
}

${ }^{1}$ Goodman Campbell Brain and Spine, Department of Neurological Surgery, and ${ }^{2}$ Department of Neurology, Indiana University School of Medicine, Indianapolis, Indiana; and '3epartment of Mathematical Sciences, Worcester Polytechnic Institute, Worcester, Massachusetts

OBJECTIVE The Massachusetts health care insurance reform law passed in 2006 has many similarities to the federal Affordable Care Act (ACA). To address concerns that the ACA might negatively impact case volume and reimbursement for physicians, the authors analyzed trends in the number of neurosurgical procedures by type and patient insurance status in Massachusetts before and after the implementation of the state's health care insurance reform. The results can provide insight into the future of neurosurgery in the American health care system.

METHODS The authors analyzed data from the Massachusetts State Inpatient Database on patients who underwent neurosurgical procedures in Massachusetts from 2001 through 2012. These data included patients' insurance status (insured or uninsured) and the numbers of procedures performed classified by neurosurgical procedural codes of the International Classification of Diseases, Ninth Revision, Clinical Modification (ICD-9-CM). Each neurosurgical procedure was grouped into 1 of 4 categories based on ICD-9-CM codes: 1) tumor, 2) other cranial/vascular, 3) shunts, and 4) spine. Comparisons were performed of the numbers of procedures performed and uninsured patients, before and after the implementation of the reform law. Data from the state of New York were used as a control. All data were controlled for population differences.

RESULTS After 2008, there were declines in the numbers of uninsured patients who underwent neurosurgical procedures in Massachusetts in all 4 categories. The number of procedures performed for tumor and spine were unchanged, whereas other cranial/vascular procedures increased. Shunt procedures decreased after implementation of the reform law but exhibited a similar trend to the control group. In New York, the number of spine surgeries increased, as did the percentage of procedures performed on uninsured patients. Other cranial/vascular procedures decreased.

CONCLUSIONS After the Massachusetts health care insurance reform, the number of uninsured individuals undergoing neurosurgical procedures significantly decreased for all categories, but more importantly, the total number of surgeries performed did not change dramatically. To the extent that trends in Massachusetts can predict the overall US experience, we can expect that some aspects of reimbursement may be positively impacted by the ACA. Neurosurgeons, who often treat patients with urgent conditions, may be affected differently than other specialists.

http://thejns.org/doi/abs/10.3171/2015.7.JNS15786

KEY WORDS Patient Protection and Affordable Care Act; Massachusetts health care reform; uninsured patients; physician compensation

$\mathrm{W}$ Iтн the passage of the federal Patient Protection and Affordable Care Act (ACA) in 2009, an estimated 30 million uninsured individuals obtained access to medical insurance..$^{4,10}$ The ACA was developed on principles similar to the 2006 Massachusetts state health care insurance reform statute, "An Act Pro- viding Access to Affordable, Quality, Accountable Health Care," also known as Chapter 58. ${ }^{9}$ The primary goal of both laws is to extend insurance coverage to nonelderly individuals who do not qualify for subsidized programs at either the state or federal levels.

The similarities of the laws include individual and busi-

ABBREVIATIONS ACA = Affordable Care Act; CPT = Current Procedural Terminology; ICD-9-CM = International Classification of Diseases, Ninth Revision, Clinical Modification; MIS = minimally invasive surgery; $\mathrm{VP}=$ ventriculoperitoneal.

ACCOMPANYING EDITORIAL See pp 165-166. DOI: 10.3171/2015.11.JNS151576.

SUBMITTED April 7, 2015. ACCEPTED July 7, 2015.

INCLUDE WHEN CITING Published online March 11, 2016; DOI: 10.3171/2015.7.JNS15786. 
ness mandates, state-based exchanges, and subsidies for lower-income individuals and families. ${ }^{3}$ Both laws require all individuals who can afford insurance to obtain a policy. If these individuals do not purchase insurance, they will be required to pay a fine. ${ }^{3}$ Both health care reforms also compel businesses to either provide insurance, or money for all employees to purchase their own health care insurance policy. The state-based exchanges consist of authorities responsible for operating a health insurance marketplace, and a website that allows citizens to compare different insurance company policies and choose a plan that best suits their medical and financial needs. ${ }^{3}$ Both statutes provide subsidies for lower-income households. These subsidies are provided for purchase of private health care insurance coverage to anyone whose income is below $400 \%$ of the federal poverty level. ${ }^{3}$

There has been significant concern that the ACA will create an acute rise in patient demand without an appropriate increase in physicians, resulting in a higher burden on doctors in a system that is already exhausting physicians. ${ }^{1}$ Because of the similarities between the Massachusetts reform and the federal ACA, Massachusetts provides a unique opportunity to observe trends in a health care system in which individuals are required to have health care insurance. ${ }^{8}$

Several studies have reported changes that occurred in Massachusetts health care since 2006, including an increase in major inpatient procedures for nonelderly, lower- and medium-income populations; an increase in minimally invasive surgeries (MISs) for nonwhite patients; reduction in measured racial disparities of patients who undergo MIS; and an increase in discretionary surgeries compared with nondiscretionary operations. ${ }^{4,6,8}$ Although 1 study included spinal surgery among all inpatient procedures, ${ }^{4}$ to our knowledge, no study has analyzed the effect of this policy change on neurosurgical procedures as a whole.

We compared data from Massachusetts before and after enactment of the Massachusetts reform to analyze changes in the number of neurosurgical procedures performed and the percentage performed on uninsured patients. Our goal is to better understand the potential effects of the ACA on neurological surgery throughout the US.

\section{Methods}

Data were obtained from the State Inpatient Database for Massachusetts and New York (the control state) using the HCUPnet online service, a segment of the Healthcare Cost and Utilization Project. This database includes demographic information on all patients discharged from hospitals in the US. Other researchers have used New York as a control ${ }^{4}$ and this is appropriate given its regional location near Massachusetts and the fact that the State Inpatient Database contains data for all years analyzed in this study. ${ }^{4}$

We grouped neurosurgical procedures into 4 categories: 1) tumor; 2) other cranial/vascular; 3) ventriculoperitoneal (VP)/thecal shunts, and 4) spine. These 4 categories have been used in other studies to predict trends in neurological surgeries and for cost analysis. ${ }^{2,7}$ All Interna- tional Classification of Diseases, Ninth Revision, Clinical Modification (ICD-9-CM) codes used for each category are listed in Table 1. The total number of surgeries and the number of procedures performed on uninsured patients were obtained for each year from 2001 through 2012 for Massachusetts and New York. The database search protocol for the State Inpatient Database was 1) specific procedures by ICD-9-CM, and 2) all listed procedures. All ICD-9-CM codes in each of the 4 categories were combined for their respective group.

All case data in this study were controlled for population differences by using a procedure/100,000 population value. The populations for Massachusetts and New York were calculated using data from the 2000 and 2010 US Censuses (www.census.gov). A linear model was developed using data points for 2000 and 2010 that allowed calculation of population increases each year, with the assumption of linear increases in population from 2001 to 2012.

For statistical analysis, each subclass of data was divided into 2 groups. The first group was from 2001 through 2007 and the second was from 2008 through 2012. The 2008-2012 group was considered separated enough from the policy changes in 2006 to provide an opportunity to observe differences. A p value $<0.05$ was considered statistically significant. An ANCOVA was used to test for differences in slopes and intercepts of the regression lines for the two groups.

To test for different slopes, we used the following formulas:

$$
\begin{aligned}
& \text { Full model: } \mathrm{Y}_{\mathrm{ij}}=\mu+\tau \mathrm{I}_{\mathrm{ij}}+\gamma \mathrm{x}_{\mathrm{ij}}+\beta \mathrm{x}_{\mathrm{ij}} \mathrm{I}_{\mathrm{ij}}+\varepsilon_{\mathrm{i}} \\
& \text { Reduced model: } \mathrm{Y}_{\mathrm{ij}}=\mu+\tau \mathrm{I}_{\mathrm{ij}}+\gamma \mathrm{x}_{\mathrm{ij}}+\varepsilon_{\mathrm{i}}
\end{aligned}
$$

in which $\mu$ is an overall mean, $\tau$ is the fixed treatment effects of Group 1, $x_{i j}$ is the centered data of the $j^{\text {th }}$ observation in group $1, \mathrm{I}_{\mathrm{ij}}$ is an indicator, and $\mathrm{I}_{\mathrm{ij}}=1$ if $\mathrm{x}_{\mathrm{ij}}$ is in Group 1, otherwise $\mathrm{I}_{\mathrm{ij}}=-1$.

These models show that the interaction item has an effect on the slope of the regression line. If the coefficient of the interaction was significant $(\beta \neq 0)$, there was a significant difference between the slopes of the regression lines of the two groups. We could then conclude that there were significant differences between the two groups. If the coefficient of the interaction was not significant $(\beta=$ 0 ), we continued to test whether they had different intercepts:

$$
\begin{aligned}
& \text { Full model: } \mathrm{Y}_{\mathrm{ij}}=\mu+\tau \mathrm{I}_{\mathrm{ij}}+\gamma \mathrm{X}_{\mathrm{ij}}+\varepsilon_{\mathrm{i}} \\
& \text { Reduced model: } \mathrm{Y}_{\mathrm{ij}}=\mu+\gamma \mathrm{X}_{\mathrm{ij}}+\varepsilon_{\mathrm{i}}
\end{aligned}
$$

If the coefficient of the indicator was significant $(\tau \neq 0)$, there was a significant difference between the intercepts of the regression lines of the two groups. We could then conclude that there were significant differences between the two groups. Otherwise, we could not reject the null hypothesis that procedure rates were the same for the two groups. 
TABLE 1. All neurosurgical ICD-9-CM procedure codes analyzed in Massachusetts and New York (2001-2012)

\begin{tabular}{|c|c|}
\hline Code & Tumor Procedure \\
\hline 1.11 & Closed (percutaneous) (needle) biopsy of cerebral meninges \\
\hline 1.12 & Biopsy of cerebral meninges \\
\hline 1.13 & Closed (percutaneous) (needle) biopsy of brain \\
\hline 1.14 & Open biopsy of brain \\
\hline 1.15 & Biopsy of skull \\
\hline 1.51 & Excision of lesion or tissue of cerebral meninges \\
\hline 1.59 & Other excision or destruction of lesion or brain tissue \\
\hline 1.6 & Excision of lesion of skull \\
\hline 4.01 & Excision of acoustic neuroma \\
\hline 7.59 & Other operations on pineal gland \\
\hline 7.61 & Partial excision of pituitary gland, transfrontal approach \\
\hline 7.62 & Partial excision of pituitary gland, transsphenoidal approach \\
\hline 7.63 & Partial excision of pituitary gland, unspecified approach \\
\hline 7.64 & Total excision of pituitary gland, transfrontal approach \\
\hline 7.65 & Total excision of pituitary gland, transsphenoidal approach \\
\hline \multirow[t]{2}{*}{7.69} & Total excision of pituitary gland, unspecified approach \\
\hline & Spine \\
\hline 81.03 & Other cervical fusion, posterior technique \\
\hline 81.05 & Dorsal and dorsolumbar fusion, posterior technique \\
\hline 81.08 & Lumbar and lumbosacral fusion, posterior technique \\
\hline 81.33 & Refusion of other cervical spine, posterior technique \\
\hline 81.35 & $\begin{array}{l}\text { Refusion of dorsal and dorsolumbar spine, posterior } \\
\text { technique }\end{array}$ \\
\hline 81.38 & $\begin{array}{l}\text { Refusion of lumbar and lumbosacral spine, posterior } \\
\text { technique }\end{array}$ \\
\hline 81.02 & Other cervical fusion, anterior technique \\
\hline 81.04 & Dorsal and dorsolumbar fusion, anterior technique \\
\hline 81.06 & Lumbar and lumbosacral fusion, anterior technique \\
\hline 81.32 & Refusion of other cervical spine, anterior technique \\
\hline 81.34 & $\begin{array}{l}\text { Refusion of dorsal and dorsolumbar spine, anterior } \\
\text { technique }\end{array}$ \\
\hline 81.36 & $\begin{array}{l}\text { Refusion of lumbar and lumbosacral spine, anterior } \\
\text { technique }\end{array}$ \\
\hline 81.07 & $\begin{array}{l}\text { Lumbar and lumbosacral fusion, lateral transverse process } \\
\text { technique }\end{array}$ \\
\hline 81.01 & Atlas-axis spinal fusion \\
\hline 81.31 & Refusion of atlas-axis spine \\
\hline 81.37 & $\begin{array}{l}\text { Refusion of lumbar and lumbosacral spine, lateral trans- } \\
\text { verse process technique }\end{array}$ \\
\hline 81 & Spinal fusion, not otherwise specified \\
\hline \multirow[t]{2}{*}{81.39} & Refusion of spine, not elsewhere classified \\
\hline & Other Cranial/Vascular \\
\hline 38.11 & Endarterectomy of intracranial vessels \\
\hline 38.12 & Endarterectomy of other vessels of head and neck \\
\hline 38.31 & Resection of intracranial vessels with anastomosis \\
\hline 38.32 & $\begin{array}{l}\text { Resection of other vessels of head and neck with anasto- } \\
\text { mosis }\end{array}$ \\
\hline 38.41 & Resection of intracranial vessels with replacement \\
\hline 38.81 & Other surgical occlusion of intracranial vessels \\
\hline
\end{tabular}

CONTINUED IN NEXT COLUMN »
» CONTINUED FROM PREVIOUS COLUMN

TABLE 1. All neurosurgical ICD-9-CM procedure codes analyzed in Massachusetts and New York (2001-2012)

\begin{tabular}{|c|c|}
\hline Code & Tumor Procedure \\
\hline \multicolumn{2}{|r|}{ Other Cranial/Vascular (continued) } \\
\hline 38.82 & Other surgical occlusion of other vessels of head and neck \\
\hline 39.28 & Extracranial-intracranial (EC-IC) vascular bypass \\
\hline 39.51 & Aneurysm clipping \\
\hline 39.52 & Other repair of aneurysm \\
\hline 39.72 & $\begin{array}{l}\text { Endovascular repair or occlusion of head and neck } \\
\text { vessels }\end{array}$ \\
\hline 39.79 & Other endovascular repair of other vessels \\
\hline 1.21 & Incision and drainage of cranial sinus \\
\hline 1.23 & Reopening of craniotomy site \\
\hline 1.24 & Other craniotomy \\
\hline 1.25 & Other craniectomy \\
\hline 1.31 & Incision of cerebral meninges \\
\hline 1.32 & Lobotomy and tractotomy \\
\hline 1.39 & Other incision of brain \\
\hline 1.52 & Hemispherectomy \\
\hline 1.53 & Lobectomy of brain \\
\hline 2.01 & Opening of cranial suture \\
\hline 4.02 & Division of trigeminal nerve \\
\hline 4.05 & Gasserian ganglionectomy \\
\hline 4.41 & Decompression of trigeminal nerve root \\
\hline 4.42 & Other cranial nerve decompression \\
\hline 1.22 & Removal of intracranial neurostimulator lead(s) \\
\hline 1.41 & Operations on thalamus \\
\hline 1.42 & Operations on globus pallidus \\
\hline \multicolumn{2}{|r|}{ VP/Thecal Shunts } \\
\hline 2.31 & Ventricular shunt to structure in head and neck \\
\hline 2.32 & Ventricular shunt to circulatory system \\
\hline 2.33 & Ventricular shunt to thoracic cavity \\
\hline 2.34 & Ventricular shunt to abdominal cavity and organs \\
\hline 2.35 & Ventricular shunt to urinary system \\
\hline 2.41 & Irrigation and exploration of ventricular shunt \\
\hline 2.42 & Replacement of ventricular shunt \\
\hline 2.43 & Removal of ventricular shunt \\
\hline 3.71 & Spinal subarachnoid-peritoneal shunt \\
\hline 3.72 & Spinal subarachnoid-ureteral shunt \\
\hline 3.79 & Other shunt of spinal theca \\
\hline 3.97 & Revision of spinal thecal shunt \\
\hline 3.98 & Removal of spinal thecal shunt \\
\hline
\end{tabular}

There was a small subset of patients in the Massachusetts database for whom insurance status data were missing. Although these values were less than $0.06 \%$ of all cases, to account for the missing data, we used the most traditional and common approach and simply omitted cases with missing data and analyzed the remaining data. Thus, we calculated the procedure per 100,000 population and uninsured neurosurgical procedures per 100,000 population values as follows: 
procedures per $100,000=100,000 \times($ number of cases - missing cases / population - missing cases)

uninsured procedures per 100,000 $=100,000 \times$ (number of uninsured cases / population - missing cases)

\section{Results}

Table 2 shows the demographic breakdown of all neurosurgical procedures in Massachusetts and New York from 2001 through 2012. During these 12 years, 191,908 neurosurgical procedures were performed in Massachusetts. Of these procedures, $12,295(6.41 \%)$ were performed on patients $0-17$ years old; $39,008(20.33 \%)$ on individuals 18-44 years old; 72,363 (37.71\%) on individuals 45-64 years old; and $68,217(35.54 \%)$ on individuals 65 years of age or older. In the total group, 97,448 patients (50.78\%) were male and 94,453 (49.22\%) were female.

By comparison, from 2001 through 2012, a total of 525,471 neurosurgical procedures were performed in New York. The age breakdown for patients in this data set is as follows: 35,061 individuals $(6.67 \%)$ were $0-17$ years old; $114,409(21.77 \%)$ were $18-44$ years old; 202,088 (38.46\%) were 45-64 years old; and 173,898 (33.09\%) were 65 years of age or older.

The State Inpatient Database had a small number of patients in both Massachusetts and New York for whom age or sex was unknown. In Massachusetts, there were 32 patients, or $0.02 \%$ of the total, with missing data, and for New York 20 patients, or $0.004 \%$. In addition, there were some patients in the Massachusetts group for whom insurance status was unknown; this included 118 patients, or $0.06 \%$ of the total data.

From 2001 through 2012, our linear population model showed that the Massachusetts population increased by nearly 20,000 people per year, and the New York population increased by more than 40,000 per year.

Our analysis of the number of neurosurgical procedures performed on uninsured patients in Massachusetts showed a statistically significant decrease in all 4 categories during 2008-2012 compared with 2001-2007. Figure 1 shows this decline in uninsured patients after health care reform for tumor (test slope $\mathrm{p}=0.0355$ ), other cranial/vascular (test slope $\mathrm{p}=0.0066$ ), $\mathrm{VP} /$ thecal shunts (test slope $\mathrm{p}=0.1580$, test intercept $\mathrm{p}=0.0091$ ), and spine (test slope $p<0.0001)$. The lowest ratios of uninsured patients who underwent neurosurgical procedures per 100,000 population after health care reform in Massachusetts were 0.76 for tumor (Fig. 2A), 0.11 for VP/thecal shunts (Fig. 2C), 0.96 for other cranial/vascular (Fig. 2E), and 0.67 for spine (Fig. 2G).

Figure $2 \mathrm{H}$ shows that the only significant change in neurosurgical procedures on uninsured patients in New York was an increase in spine surgeries (test slope $\mathrm{p}=$ 0.9261 , test intercept $p=0.0479$ ). The lowest uninsured ratios per 100,000 people in New York after 2006 were 0.59 for tumor (Fig. 2B), 0.17 for VP/thecal shunts (Fig. 2D), 1.37 for other cranial/vascular (Fig. 2F), and 1.36 for spine (Fig. 2H).

Figure $2 \mathrm{~A}, \mathrm{C}, \mathrm{E}$, and $\mathrm{G}$ show trends in total neurosurgical procedure numbers for all 4 subspecialty categories.
TABLE 2. Demographic information for patients undergoing neurosurgical procedures in Massachusetts and New York (2001-2012)*

\begin{tabular}{lcc}
\hline \multicolumn{1}{c}{ Demographic } & Massachusetts & New York \\
\hline Total cases (\%) & $191,908(100)$ & $525,471(100)$ \\
\hline Age (yrs) & & \\
\hline $0-17$ & $12,295(6.41)$ & $35,061(6.67)$ \\
\hline $18-44$ & $39,008(20.33)$ & $114,409(21.77)$ \\
\hline $45-64$ & $72,363(37.71)$ & $202,088(38.46)$ \\
\hline $65+$ & $68,217(35.54)$ & $173,898(33.09)$ \\
\hline Sex & & \\
\hline Male & $97,448(50.78)$ & $264,471(50.33)$ \\
\hline Female & $94,453(49.22)$ & $260,995(49.67)$ \\
\hline Missing age or sex data & $32(0.02)$ & $20(0.004)$ \\
\hline Missing insurance status data & $118(0.06)$ & $0(0)$ \\
\hline
\end{tabular}

* All data given as number of cases (\%).

In Massachusetts, there was no change in total procedures for tumor (test slope $\mathrm{p}=0.4019$ and test intercept $\mathrm{p}=$ 0.4158 ) and spine (test slope $p=0.6799$ and test intercept $\mathrm{p}=0.1304$ ) after the policy reform. There was a significant decrease in total shunt cases after 2007 (test slope $\mathrm{p}=0.0269$ ), as well as an increase in other/cranial total cases in this same time period (test slope $p=0.0016$ ). In New York, there was no statistically significant change in the total cases for tumor (test slope $p=0.3121$ and test intercept $\mathrm{p}=0.7689$ ) and $\mathrm{VP} /$ thecal shunts (test slope $\mathrm{p}=$ 0.1002 and test intercept $p=0.9645$ ) after 2007. Other cranial/vascular case totals decreased (test slope $p=0.0355$ ) and spine case totals increased $(\mathrm{p}=0.0007)$ in this same time period.

Figure 3 shows the percentage of cases performed on individuals with some form of insurance for both Massachusetts and New York in all years examined in this study. Forms of health insurance included Medicare, Medicaid, private insurance, worker's compensation, TRICARE/ CHAMPUS, CHAMPVA, Title V, and other government programs. This graph shows a gradual increase in the percentage of cases performed on insured individuals after the policy change, resulting in an insured percentage of well over $98 \%$ for all 4 categories of procedures by 2012 .

\section{Discussion}

Several studies have used the 2006 Massachusetts health care policy as a model to predict the impact of the ACA., ${ }^{4,5}$ To our knowledge, this is the first study to examine the impact of this reform on neurological surgery as a whole. Our data show a significant decrease in the percentages of uninsured individuals undergoing all categories of neurosurgical procedures in Massachusetts after its health care policy change. This result is not surprising because the health care insurance law required all individuals to obtain health care insurance. Similar results have been reported in other studies. Toussaint et al. examined orthopedic trauma surgeries in Boston before and after the state's policy change. ${ }^{12}$ They reported a decrease in un- 


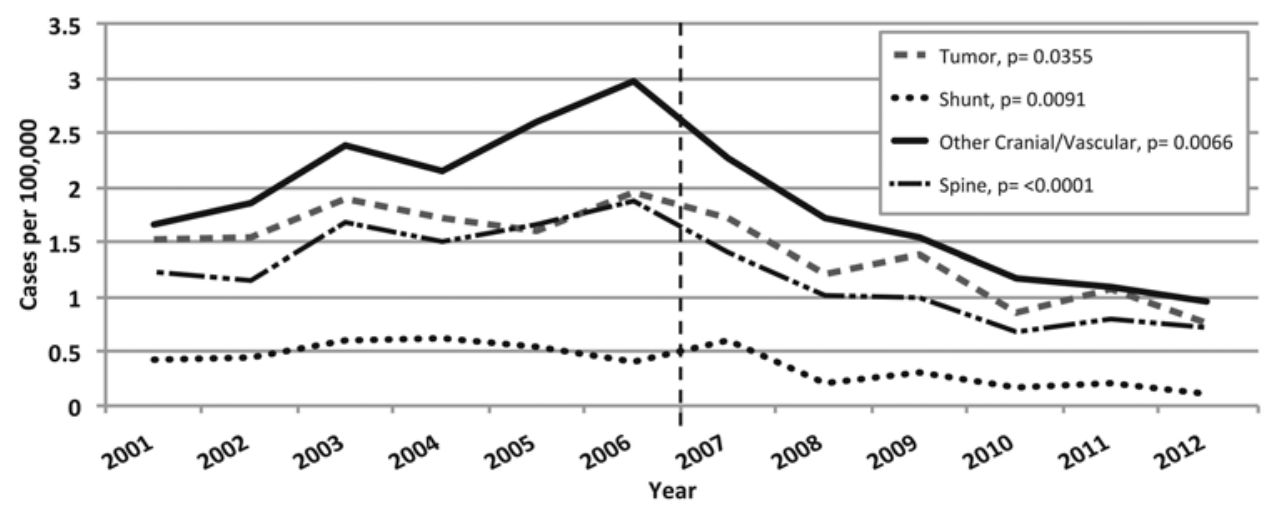

FIG. 1. Linear graph showing the trend in uninsured cases for tumor, VP/thecal shunts, other cranial/vascular, and spine in Massachusetts from 2001 to 2012. The vertical dotted line represents the implementation of the Massachusetts health care insurance reform.

insured orthopedic trauma patients from $23.8 \%$ to $14.4 \%$ from 2000 to $2010 .^{12}$ Interestingly, they still observed an uninsured rate of more than $14 \%$ after the policy change. Our study showed a significant decrease in uninsured patients after 2008 for all subspecialties. The highest uninsured rate noted in our study was for the $2007 \mathrm{VP} /$ thecal shunt subgroup, which was $3.5 \%$ of surgeries or 0.59 cases per 100,000 population. The observation that neurosurgical uninsured rates were less than those reported in the Toussaint et al. study suggests that trauma patients comprise a smaller portion of the total neurosurgical patient population, resulting in a higher percentage of procedures performed on an elective basis. Regardless of the specialty, studies consistently show a significant decline in uninsured cases in Massachusetts after its health care policy change.

The decline in uninsured cases is important to note, but it does not show the full impact of the policy change. Several studies have shown increases in the number of surgical procedures in Massachusetts after 2006. Ellimoottil et al. examined the effect of the policy on discretionary versus nondiscretionary surgeries. ${ }^{4}$ They defined discretionary as elective inpatient procedures and nondiscretionary as surgeries that addressed an immediate life-threatening condition. They showed a significant increase in discretionary surgeries and a concordant decrease in nondiscretionary surgeries after the reform. ${ }^{4}$ Another study that examined the effect of the policy on MIS showed an increase in nonwhite individuals undergoing MIS after $2006 .{ }^{8}$ Our study showed an increase in only 1 subspecialty category, other cranial/vascular. Although we noted a statistically significant increase, the postreform case volume plateaued after only 3 years (Fig. 2E). The control state (New York) showed a statistically significant decline in the other cranial/vascular category. Massachusetts' increase in other cranial/vascular procedures is consistent with the national trend, but we are not able to explain why New York had a decline in this category. Other than the increase in other cranial/vascular surgeries, we found no increase in procedures or procedure trends in Massachusetts. Tumor cases had no significant change, and VP/thecal shunt surgeries decreased. New York had no changes in the number of procedures for either of these categories. Although spine case volume increased after the new policy, the rate at which it increased was not different than the pre-policy trajectory; therefore the policy did not cause an increase in spine surgery volume in Massachusetts. The rate of spine procedure volume did increase in New York. Our study shows that after the Massachusetts health care insurance reform, total surgery numbers did not dramatically increase in the majority of neurosurgical specialties. This result has been observed in other research. Ellimoottil et al. examined urological surgeries in Massachusetts after the reform. ${ }^{5}$ Although they found an increase in nonwhite and low-income patients undergoing surgeries, there was no significant change in overall urological surgeries. ${ }^{5}$ Previous data and our study show that in certain specialties, mandated health care insurance does not result in increased case totals. The most likely explanation for this finding is that most clinical conditions that require neurosurgical procedures are sufficiently urgent that patients present themselves for care irrespective of their insurance coverage. In addition, the neurosurgeons who evaluate these patients typically offer appropriate surgical treatment irrespective of insurance payments.

The results of this study show a significant impact of policy changes on physician and hospital reimbursement for neurosurgical procedures. If the patient population remains stable and the percentage of insured patients increases, there is a potential for higher reimbursement per patient. However, the total reimbursement to a practitioner depends on the overall payer mix. A major concern for some with regard to the ACA, however, is whether reimbursement rates per procedure will decrease to compensate for the increase in the percentage of patients covered by insurance. ${ }^{11}$ Rosenow et al. conducted a survey of neurosurgeons with regard to Medicare reimbursements, and found that neurosurgeons are less likely to accept Medicare patients as rates continue to decrease. ${ }^{11}$ If procedure rates decline, overall reimbursements may not increase as the insured population increases. A major influence in this debate is whether the previously uninsured patients will obtain government-funded coverage, or whether the ACA will push these individuals into the private sector. Another 
A Total Tumor Cases per 100,000 in Massachusetts and New York from 2001 to 2012

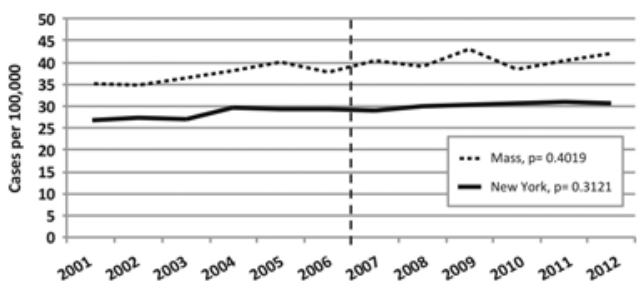

Year

C Total VP/Thecal Shunt Cases per 100,000 in Massachusetts and New York from 2001 to 2012

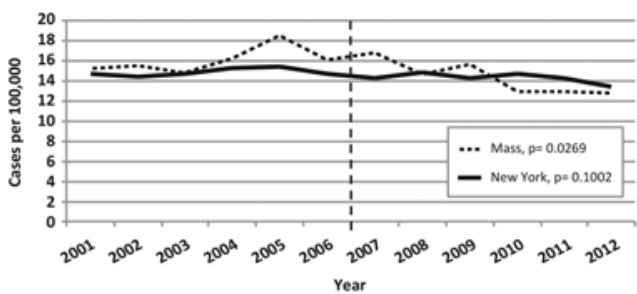

E Total Other Cranial and Vascular Cases per 100,000 in Massachusetts and New York from 2001 to 2012

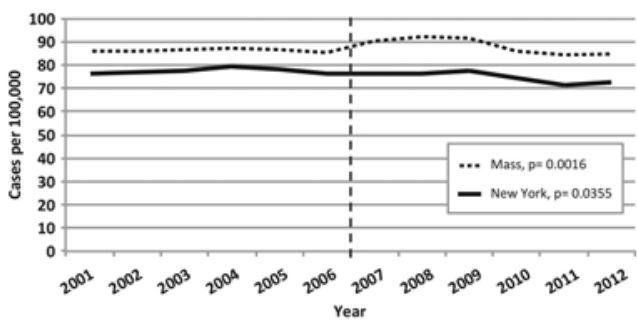

G Total Spine Cases per 100,000 in Massachusetts and New York from 2001 to 2012

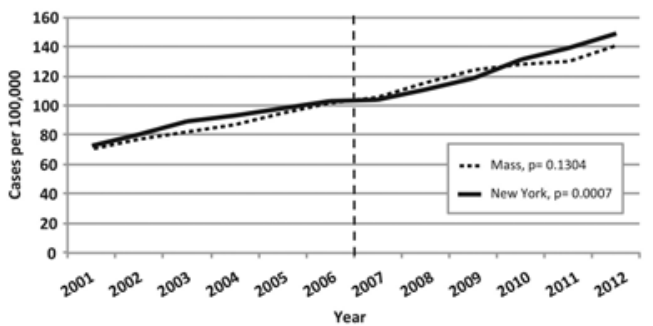

B Uninsured Tumor Cases per 100,000 in Massachusetts and New York from 2001 to 2012

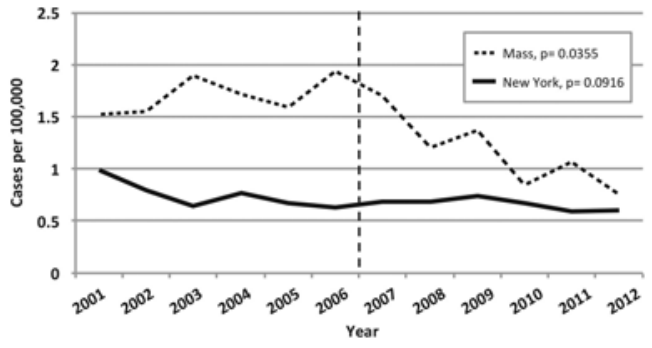

D Uninsured VP/Thecal Shunt Cases per 100,000 in Massachusetts and New York from 2001 to 2012

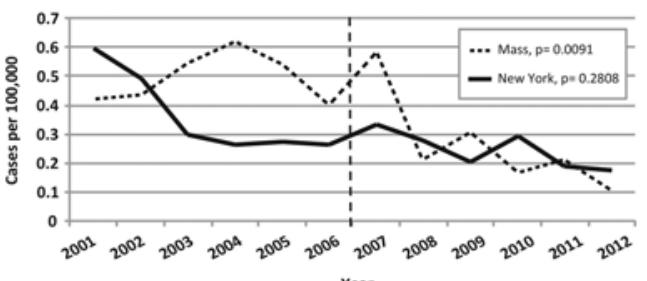

Year

F Uninsured Other Cranial and Vascular Cases per 100,000 in Massachusetts and New York from 2001-2012

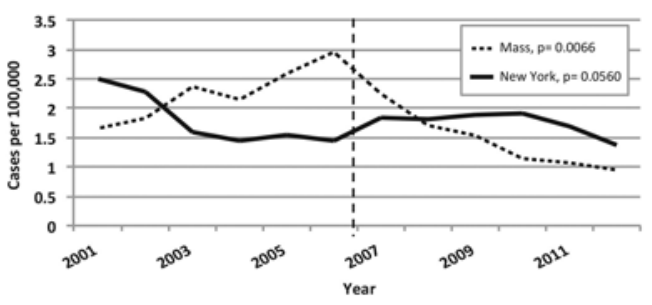

H Uninsured Spine Cases per 100,000 in Massachusetts

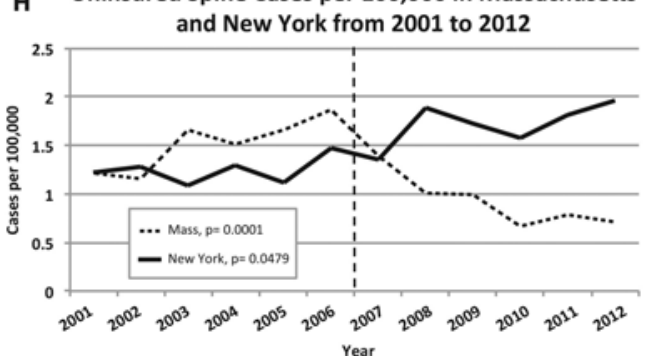

FIG. 2. Linear graphs displaying the trends in total surgeries (A, C, E, and $\mathbf{G})$ as well as surgeries on uninsured patients $(\mathbf{B}, \mathbf{D}, \mathbf{F}$, and $H$ ) for tumor ( $A$ and $B)$, VP/thecal shunts (C and D), other cranial/vascular ( $E$ and $F)$, and spine $(G$ and $H)$ in Massachusetts and New York from 2001 to 2012. Mass = Massachusetts.

concern is that patients with higher-paying private insurance plans will transition to ACA health care coverage, resulting in lower reimbursement rates for procedures. There are two possible causes for this shift: either employers will no longer provide private insurance to their employees, and allow them to obtain coverage through the ACA, or individuals will decide to obtain an ACA plan because of the anticipation of lower policy rates. Future research is needed to make these distinctions.

Our study has some limitations. The first is that our data from the State Inpatient Database is based on ICD9-CM procedure codes. It is more common for procedures to be billed as Current Procedural Terminology (CPT) codes. These two are not interchangeable, and they use different categories and specifications. Our list of ICD-9$\mathrm{CM}$ procedure codes for neurosurgery is all-inclusive, but not as specific as CPT codes. Despite the lack of a CPT database, ICD-9-CM procedure codes have been widely used in research and are thus appropriate for our study. The fact that the same method was used for both Massachusetts and New York should make relative comparisons accurate even if he exact numbers are not.

Another limitation of our study is that the demographic makeup of Massachusetts differs from the national averages. When comparing Massachusetts with the US as a whole, the 2010 census showed that the Massachusetts 


\section{A Percentage of Tumor Surgeries Performed on Individuals with Insurance in Massachusetts and New York from 2001 to 2012}

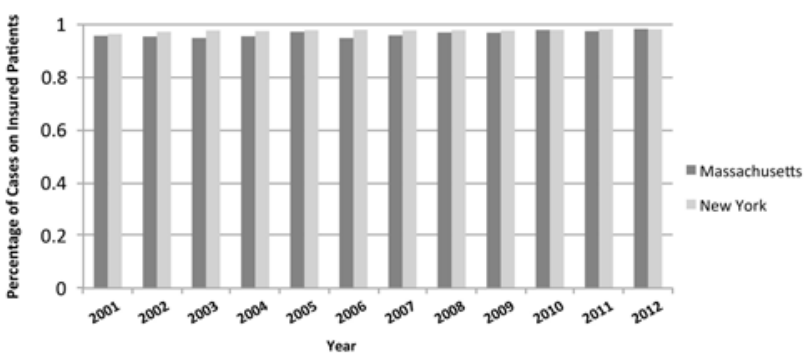

\section{Percentage of Other Cranial and Vascular Surgeries Performed on Individuals with Insurance in Massachusetts and New York from 2001 to 2012}

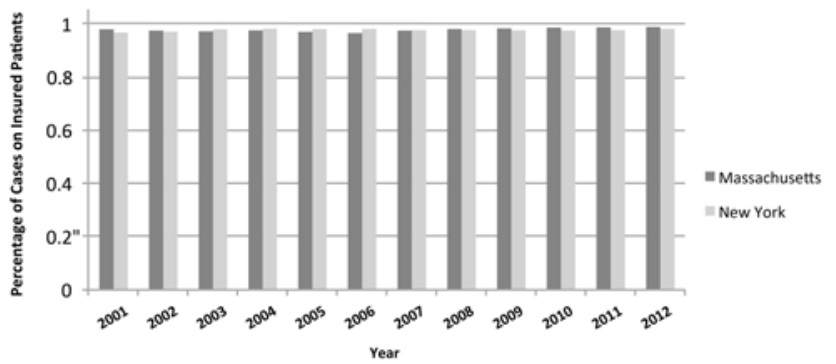

FIG. 3. Bar graphs showing the trend in insured cases for tumor (A), VP/thecal shunts (B), other cranial/vascular (C), and spine (D) in Massachusetts and New York from 2001 to 2012.

\section{B Percentage of VP/Thecal Shunt Surgeries \\ Performed on Individuals with Insurance \\ in Massachusetts and New York from 2001 to 2012}

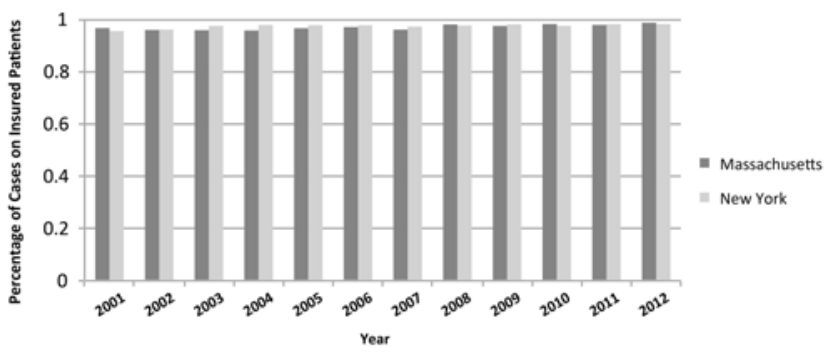
D Percentage of Spine Surgeries Performed on Individuals with Insurance in Massachusetts and New York from 2001 to 2012

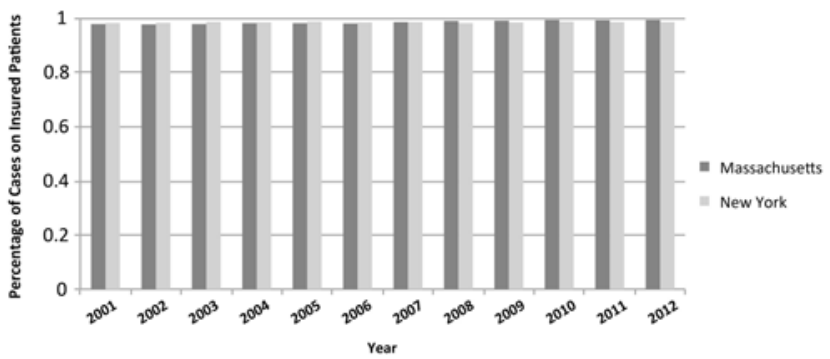

Caucasian population was $83.2 \%$ while the national average was $77.7 \% .^{1}$ Its African American population was $8.1 \%$ compared with a national average of $13.2 \%$, and its Hispanic population was $10.5 \%$ compared with the national population of $17.1 \% .^{1}$ Moreover, the median household income in Massachusetts was more than $\$ 13,000$ higher than the national average $(\$ 66,866$ vs $\$ 53,046) .{ }^{1}$ The differences in demographics and the financial status of Massachusetts citizens do pose challenges when extrapolating the health care insurance trends in Massachusetts compared with the national impact of the ACA, especially in a system that has racial disaparities. ${ }^{8}$ Moreover, it is difficult to extrapolate national trends in procedure amounts when examining changes in only 2 states. Nevertheless, data from Massachusetts still offer an opportunity to predict neurosurgical health care trends in a system in which all individuals are required to have health insurance.

More work is needed to better understand the full impact of the ACA on the practice of neurosurgery. This study has established that there was not a dramatic increase in patient volume after state law required all individuals to have health insurance, but there was a significant decrease in uninsured patients undergoing procedures. An understanding of the payer-mix changes in the neurosurgical patient population after a policy change will provide a better understanding of the impact on procedure reimbursements for neurosurgeons. Future work is also needed to analyze changes in racial disparities in neurosurgery after the policy change. Studies have shown increases in the number of surgeries in nonwhite individuals in Massachusetts after
$2006.4,5,8$ No studies, however, have analyzed this in relation to neurosurgical patients specifically, and this would certainly add to our understanding of this policy's impact on access to neurosurgical care for minorities.

\section{Conclusions}

Using Massachusetts as a model, our study has established that in a system that requires individuals to have health care insurance, neurosurgical procedures do not significantly change. Although the case volume remains relatively stable, the percentage of uninsured patients decreases, resulting in a potentially positive impact on reimbursement. When extrapolating the Massachusetts experience to the ACA, neurosurgery, which treats patients with more urgent conditions, may be affected differently from other specialties.

\section{Acknowledgments}

We thank Dr. Chandy Ellimoottil of the University of Michigan for his perspective and advice regarding this study, and Marilyn Yurk at Indiana University for help with editing the manuscript.

\section{References}

1. Anderson A: The impact of the Affordable Care Act on the health care workforce. Heritage Foundation. March 18, 2014. (http://www.heritage.org/research/reports/2014/03/theimpact-of-the-affordable-care-act-on-the-health-care-workforce ) [Accessed December 30, 2015]

2. Brinjikji W, Kallmes DF, Lanzino G, Cloft HJ: Hospitalization costs for endovascular and surgical treatment of ruptured 
aneurysms in the United States are substantially higher than Medicare payments. AJNR Am J Neuroradiol 33:10371040, 2012

3. Burdett G: Romneycare vs. Obamacare: key similarities \& differences. CBS Boston. November 13, 2013. (http://boston. cbslocal.com/2013/11/13/romneycare-vs-obamacare-keysimilarities-differences/ ) [Accessed December 30, 2015]

4. Ellimoottil C, Miller S, Ayanian JZ, Miller DC: Effect of insurance expansion on utilization of inpatient surgery. JAMA Surg 149:829-836, 2014

5. Ellimoottil C, Miller S, Wei JT, Miller DC: Anticipating the impact of insurance expansion on inpatient urological surgery. Urol Pract 1:134-140, 2014

6. Hanchate AD, Lasser KE, Kapoor A, Rosen J, McCormick D, D'Amore MM, et al: Massachusetts reform and disparities in inpatient care utilization. Med Care 50:569-577, 2012

7. Hughey AB, Lesniak MS, Ansari SA, Roth S: What will anesthesiologists be anesthetizing? Trends in neurosurgical procedure usage. Anesth Analg 110:1686-1697, 2010

8. Loehrer AP, Song Z, Auchincloss HG, Hutter MM: Massachusetts health care reform and reduced racial disparities in minimally invasive surgery. JAMA Surg 148:1116-1122, 2013

9. McDonough JE, Rosman B, Butt M, Tucker L, Howe LK: Massachusetts health reform implementation: major progress and future challenges. Health Aff (Millwood) 27:w285w297, 2008

10. Rosenbaum S: The Patient Protection and Affordable Care Act: implications for public health policy and practice. Public Health Rep 126:130-135, 2011

11. Rosenow JM, Orrico KO: Neurosurgeons' responses to changing Medicare reimbursement. Neurosurg Focus 37(5):E12, 2014
12. Toussaint RJ, Bergeron SG, Weaver MJ, Tornetta P III, Vrahas MS, Harris MB: The effect of the Massachusetts healthcare reform on the uninsured rate of the orthopaedic trauma population. J Bone Joint Surg Am 96:e141, 2014

\section{Disclosures}

The authors report no conflict of interest concerning the materials or methods used in this study or the findings specified in this paper.

\section{Author Contributions}

Conception and design: Villelli, Das, Zou, Barbaro. Acquisition of data: Villelli. Analysis and interpretation of data: Zou. Drafting the article: Villelli. Critically revising the article: Das, Huff, Barbaro. Reviewed submitted version of manuscript: all authors. Statistical analysis: Yan.

\section{Supplemental Information Previous Presentations}

An abstract of this study was given as an oral presentation at the 2015 CNS Annual Meeting in New Orleans, Louisiana, September $26-30,2015$.

\section{Correspondence}

Nicolas Villelli, Goodman Campbell Brain and Spine, Department of Neurological Surgery, Indiana University School of Medicine, 355 W. 16th St., GH 5100, Indianapolis, IN 46202. email: nwvillel@iupui.edu. 